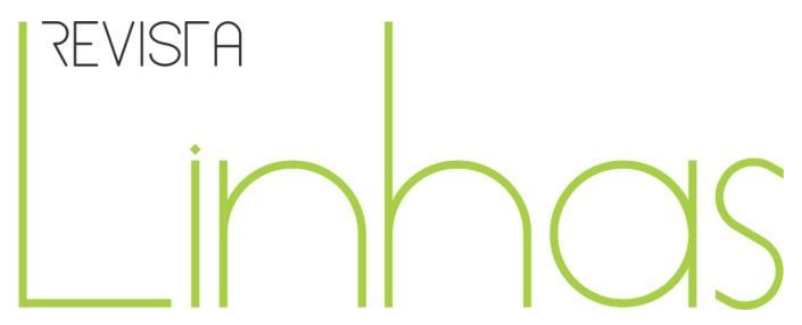

\title{
Marcas de uma pedagogia tecida nas relações: documentação pedagógica como narrativa da experiência educativa na creche
}

\begin{abstract}
Resumo
O presente texto tem por tema o processo de documentação pedagógica como narrativa da experiência educativa na creche. Como recurso argumentativo, apresentam-se elementos de uma pesquisa de doutorado em educação, realizada na cidade de Pistóia, na Itália. Dentre os aspectos privilegiados, busca-se conhecer as documentações produzidas no contexto de quatro creches, suas diferentes formas, tipos e, sobretudo, os fios comuns e o entrelaçamento que compõe seu tecido narrativo. Como filtros de leitura, têm-se as proposições da pedagogia italiana, Malaguzzi (1999), Rinaldi (2012) em diálogo com a filosofia de Walter Benjamin. A proposição é que a documentação pedagógica é uma narrativa que oferece visibilidade e sustenta as experiências educativas na creche. Considerando suas diferentes formas e tipos, encontraram-se, nas documentações, dois fios comuns: uma imagem de criança ativa, com capacidade para crescer e se relacionar, e um contexto educativo potencialmente rico em experiência. $O$ entrelaçamento dos fios acontece nas relações entre professores, crianças e suas famílias. No gesto de documentar há a produção de um tecido narrativo capaz de sustentar o encontro, as relações e as experiências no contexto educativo. Trata-se de uma aposta no processo de documentação pedagógica que demanda não apenas uma técnica, mas uma posição ética frente ao outro.
\end{abstract}

Palavras-chave: Creche. Documentação Pedagógica. Narrativa. Relações. Experiência.

\section{Para citar este artigo:}

PANDINI-SIMIANO, Luciane; BARBOSA, Maria Carmen Silveira; SILVA, Clara Maria. Marcas de uma pedagogia tecida nas relações: documentação pedagógica como narrativa da experiência educativa na creche. Revista Linhas. Florianópolis, v. 19, n. 40, p. 200-217, maio/ago. 2018.

Luciane Pandini- Simiano

Universidade do Sul de Santa Catarina -

UNISUL - Tubarão/SC - Brasil lucianepandini@gmail.com

Maria Carmen Silveira Barbosa

Universidade Federal do Rio

Grande do Sul - UFRGS - Porto

Alegre/RS - Brasil

licabarbosa@ufrgs.br

\section{Clara Maria Silva}

Università degli Studi di Firenze -

Florença-Itália

clarasilva@unifi.it 


\title{
Trademarks of a woven pedagogy in relations: pedagogical documentation as a narrative of the educational experience at the nursery
}

\begin{abstract}
The present text has as its theme the process of pedagogical documentation as a narrative of the educational experience in day care center. As an argumentative resource, we present elements of a doctoral research in education, held in the city of Pistoia, Italy. Among the privileged aspects, it is sought to know the documentation produced in the context of four daycare centers, their different forms, types and, above all, the common threads and the interweaving that compose their narrative fabric. As reading filters we have the propositions of the Italian pedagogy, Malaguzzi (1999), Rinaldi (2012) in dialogue with the philosophy of Walter Benjamin. The proposition is that the pedagogical documentation is a narrative that offers visibility and supports the educational experiences in day care. Considering its different forms and types, two common threads were found in the documentation: an image of an active child with a capacity to grow and relate, and an educational context potentially rich in experience.

The interweaving of wires happens in the relationships between teachers, children and their families. In the gesture of documenting there is the production of a narrative capable of sustaining encounter, relationships and experiences in the educational context. It is a bet in the process of pedagogical documentation that demands not only one technique, but one ethical position in front of the other.
\end{abstract}

Keywords: Nursery. Pedagogical Documentation. Narrative. Relations. Experience. 
"Do momento em que somos um diálogo."

Hölderlin

Um dos grandes desafios contemporâneos na organização de contextos coletivos de educação infantil envolve o compartilhamento com as famílias na tarefa de educar e cuidar dos pequenos. As palavras “educação e cuidado" tramam a complexa e delicada rede, que envolve a garantia de uma proposta educativa que assegure a educação em sua integralidade, entendendo o cuidado como indissociável do processo educativo com crianças pequenas, desde bebês, sendo essa responsabilidade compartilhada com as famílias.

No diálogo com os estudos da abordagem italiana para a educação da primeira infância ${ }^{1}$ é possível encontrar diferentes autores que versam a respeito das especificidades da educação e cuidado de crianças bem pequenas na creche. Em comum, defende-se a socialização, as interações e as aprendizagens entre professores, crianças e suas famílias como pilares que sustentam a pedagogia da educação infantil. Nesse âmbito, a documentação pedagógica ganha destaque, tornando-se alvo permanente de reflexões: Qual seu significado e função na educação infantil? O que documentar? Quais os melhores instrumentos? Como construir documentações? Tais perguntas são ainda mais prementes quando falamos de bebês e crianças bem pequenas, cuja presença nos olha, interpela e remete a um encontro complexo, incerto, imprevisível.

No Brasil, é consensual, entre teóricos e pesquisadores da área, a importância da observação, registro e documentação pedagógica no contexto da educação infantil (FREIRE-WEFFORT, 1995, OSTETTO, 2008, BARBOSA, 2006). Contudo, embora as pesquisas e diretrizes legais apontem para a importância de tais práticas no contexto educativo, essas indicações não são suficientes, há dificuldades para sustentar tal processo em função de práticas pedagógicas frágeis que comumente associam a documentação à atividade burocrática, não a compreendendo como um elemento inerente ao processo educativo. Nesse contexto, é necessário criar outras perspectivas

\footnotetext{
${ }^{1}$ Ressalta-se que a pedagogia italiana não é única em todo país. Há semelhanças e diferenças entre regiões. A pedagogia à qual nos referimos neste texto localiza-se nas experiências de Reggio Emilia, Milão, Parma, São Miniatto e Pistóia (EDWARDS; GANDINI; FORMAN, 2002).
} 
para o ser professor, ser bebê e o estar na creche. Olhares atentos para as experiências, as relações, as narrativas, os movimentos constituídos e constituintes...

O presente texto aborda tais temáticas, ao propor a documentação pedagógica como uma narrativa que sustenta e oferece visibilidade às experiências educativas na creche. $\mathrm{O}$ argumento tecido do/no texto está pautado em elementos de uma pesquisa de doutorado em educação ${ }^{2}$, realizada em 2014, na cidade de Pistóia, na Itália, que pesquisou as documentações pedagógicas no contexto de quatro creches. O ponto de partida são as seguintes questões: Como se dá o processo de documentação pedagógica? Como são narradas, descritas, interpretadas e construídas tais documentações? Considerando as relações entre os professores, os bebês e suas famílias, quais são os fios comuns que tramam a documentação pedagógica e como se entrelaçam?

Com fios da teoria, no diálogo entre diferentes autores e perspectivas, como Benjamim (1984) e Malaguzzi (1995), defende-se o estabelecimento de relações educativas entre adultos e crianças como pilares que sustentam uma "pedagogia da educação infantil”. Propõe-se a documentação pedagógica como possibilidade do reconhecimento e valorização da experiência, da produção de sentido e da condição de pertença. Uma tessitura narrativa capaz de sustentar o encontro entre crianças e adultos. Trata-se de uma outra forma ética, estética e política de pensar as relações no contexto educativo.

\section{Notas sobre o processo de documentação pedagógica}

A concepção de documentação pedagógica na produção teórica italiana está relacionada à importância deste processo para dar visibilidade às experiências das crianças. O ato de documentar, nessa perspectiva, configura-se como um "processo cooperativo que ajuda os professores a escutarem as crianças com quem trabalham, possibilitando assim, a construção de experiências significativas com elas" (EDWARDS; GANDINI; FORMAN, 2002, p. 84).

\footnotetext{
${ }^{2}$ Pesquisa realizada com apoio financeiro da Coordenação de Aperfeiçoamento de Pessoal de Nível Superior-CAPES.
} 
O processo de documentação pedagógica considera a importância da escuta, da observação, do registro, da interpretação (MALAGUZZI, 1999). Nessa proposta, observação e escuta estão intimamente associadas. A escuta como princípio da documentação pedagógica pode ser compreendida como a sensibilidade a nos conectar ao outro (RINALDI, 2012). Aquilo que é realizado não com os ouvidos, mas por meio de todos os sentidos; em um tempo que não é linear, mas cheio de silêncios e pausas; uma escuta aberta às diferenças; que reconheça o valor de outros pontos de vista; que não produza respostas, mas que formule questões, convoque a interpretações; que não é fácil de ser realizada, mas é a premissa para qualquer relação de aprendizagem. A escuta do outro provoca a abertura ao inesperado. Abre-se espaço para a interpretação, a invenção, para oferecer da novidade trazida ao mundo pelas crianças.

O olhar e a escuta capturados ganham forma no registro, permitindo materializar o vivido. Anotações rápidas, escritos extensos em cadernos particulares, mapas, desenhos, gravação em áudios, vídeos e fotografias são registros realizados no contexto educativo. Importante destacar que para fazer um bom registro não se trata de captar maior número de informações e objetos possíveis. Trata-se de selecionar aquilo que faz sentido. E também inventar um sentido...

Após um número significativo de registros, é o momento de revisitar o material coletado e interpretar. Os registros são lidos, transcritos e reorganizados. As fotografias são selecionadas criando uma sequência de imagens flexíveis. As gravações em vídeo são revistas e recortadas em cenas. O tecido da documentação é organizado, alinhavado para ser compartilhado, inicialmente, com os colegas professores da creche.

A tessitura está imbuída da subjetividade daquele que tece. Após esta, se oferece à subjetividade interpretativa dos outros, de modo que o tecido possa ser conhecido, reconhecido, criado, recriado. Uma espécie de interpretação em companhia, uma vez que novas apropriações podem ser feitas no encontro com outras professoras ou, como diz a pedagogia italiana, uma ricognizione/ recognição.

De acordo com Rinaldi (1995), ricognizione significa a busca compartilhada para entender o significado dos acontecimentos. Reconhecer observações, ideias, emoções no compartilhamento com o outro. Partindo do princípio que a documentação não é uma descrição ou mera constatação do acontecido, não se pode afirmar que o que se 
documenta seja uma representação direta do que as crianças fazem e dizem. O professor registra imagens, palavras, textos, desenhos e falas das crianças, reorganiza-os compondo o tecido. Em seguida, a trama é compartilhada, lida e interpretada em companhia. O gesto de compartilhar estabelece conexões, cria hipóteses, amplia as significações, auxiliando o professor nesse sutil e delicado processo.

Escolher implica oferecer uma interpretação. Portanto, o professor na trama documentativa não se limita apenas a juntar fios aleatoriamente. A arte de tecer afirma uma condição de autoria. Nesse processo, as dificuldades, dúvidas, incertezas, vazios, podem surgir, não sendo vistos como algo negativo, mas tornam-se condição para abrirse para à invenção de novos pensamentos, possibilidades e perspectivas.

A documentação é uma narrativa que tem como principal função, auxiliar as crianças e adultos a encontrarem e elaborarem significados para o que fazem, descobrem, experimentam. Documentar, nessa perspectiva, é contar histórias que testemunhem narrativamente as experiências educativas. No compartilhamento das histórias, a documentação pode ser apresentada de muitas maneiras diferentes, incluindo, "painéis, materiais escritos a mão ou digitados, como livros, cartas, panfletos, e ainda caixas, tecidos, instalações e outros tipos de materiais. Podem ser apresentadas de todas as maneiras e combinações possíveis" (EDWARDS, GANDINI E FORMAN 2002, p. 155).

Em pesquisa nas creches de Pistóia, as documentações compostas de imagens, desenhos, fotografias, objetos bi e tridimensionais, vídeos e escritos contam a história de crianças e adultos que vivem juntos e compartilham a vida em instituições educativas. Assim como "as crianças têm cem linguagens", também os professores podem ter cem formas de documentar. Na variedade de materialidades documentativas é possível encontrar crianças reais e concretas que vivem experiências em espaços coletivos de educação. 


\section{No tecido da documentação: uma imagem de criança e um potente contexto} educativo

Uma dos fios que sustenta o tecido das documentações pesquisadas refere-se a uma imagem de infância entendida na sua alteridade ${ }^{3}$. A pedagogia italiana compreende a criança como sujeito ativo, potente, participativo no seu processo educativo. Busca-se conhecê-la a partir de suas especificidades, palavras e ações, procurando elaborar os significados do ser criança no encontro com ela mesma. Desvelar e tornar públicas as imagens de criança é fundamental, pois essas imagens condicionam o relacionamento estabelecido com elas.

Para Rinaldi (2002), a imagem é um fator determinante na constituição de relações; ao referir-se à imagem de criança pequena, destaca:

Seus olhares demonstram a intenção de se comunicar, sua curiosidade e seu desejo. Estamos falando de crianças que são pesquisadores, que procuram entender significados, que se esforçam para responder uma pergunta fundamental: o que é a vida? Percebemos que elas nos dizem algo, mesmo quando ainda não falam. (RINALDI, 2002, p. 77)

Acreditar que as crianças pequenas se comunicam e interagem com o meio e o outro mesmo quando ainda não falam, implica a construção de uma imagem diferente de bebê e criança bem pequena. Tal fato nos leva a pensar sobre a necessidade de superar os conceitos e imagens de bebê passivo, frágil, seguindo etapas rígidas de maturação e por isso necessitando de estimulação sistemática. Essas discussões ampliam nosso olhar, aproximando-nos de outras formas de compreensão desse sujeito. Deixar falar aquele que não tem voz e ouvir a quem não fala é um desafio instigante, pois nos permite inverter nosso olhar e pensar do ponto de vista de uma lógica oposta, a qual vê os bebês a partir do que eles têm e não do que lhes "falta". Pensar neles como presença e não como falta, como força e não como incapacidade (KOHAN, 2007).

A fragilidade coloca o bebê numa condição de dependência. Malaguzzi, ao assumir a dependência física e psíquica do bebê, propõe-nos lançar um outro olhar sobre a

\footnotetext{
${ }^{3}$ Segundo Larrosa (1998, p. 70), reconhecer a alteridade da criança é algo radical que deve ser compreendido: nada mais, nada menos do que a sua absoluta heterogeneidade no que diz respeito a nós e a nosso mundo, sua absoluta diferença.
} 
mesma. Para ele, a imaturidade da criança não é impotência, mas possibilidade, potencialidade para crescer e se relacionar. (MALAGUZZI (1999) apud HOYUELOS, 2004, p. 75). Os bebês são ativos e manifestam-se ao outro por intermédio de seus meios de comunicação e expressão, revelando formas e ritmos próprios na relação. Na esteira desse pensamento, entendendo a criança pequena como um ser de relação, com ampla capacidade para interagir com o outro desde o nascimento, compreende-se o bebê como um sujeito constituído e constituinte de relações.

Em outra perspectiva teórica, Benjamin relaciona metaforicamente a criança bem pequena a um caçador: "Mal entra na vida ela é caçador. Caça os espíritos cujo rastro fareja nas coisas [...]. Para ela tudo se passa como em sonhos: ela não conhece nada de permanente; tudo lhe acontece, pensa ela, vai-Ihe de encontro" (BENJAMIM, 1994, p. 39, grifos nossos).

Figura 1: Documentação Tuttoaccade per La prima volta - Nido Il Grillo

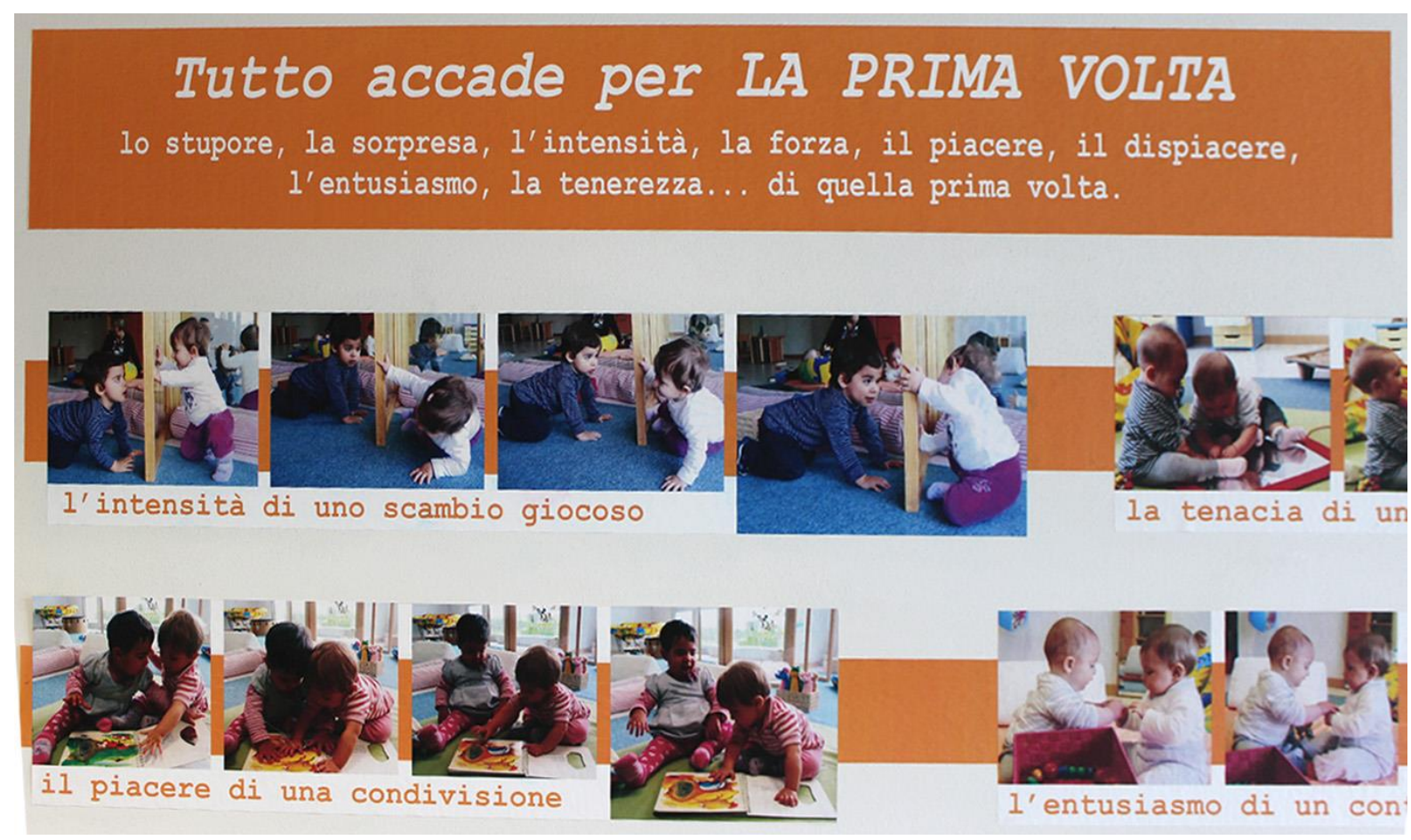



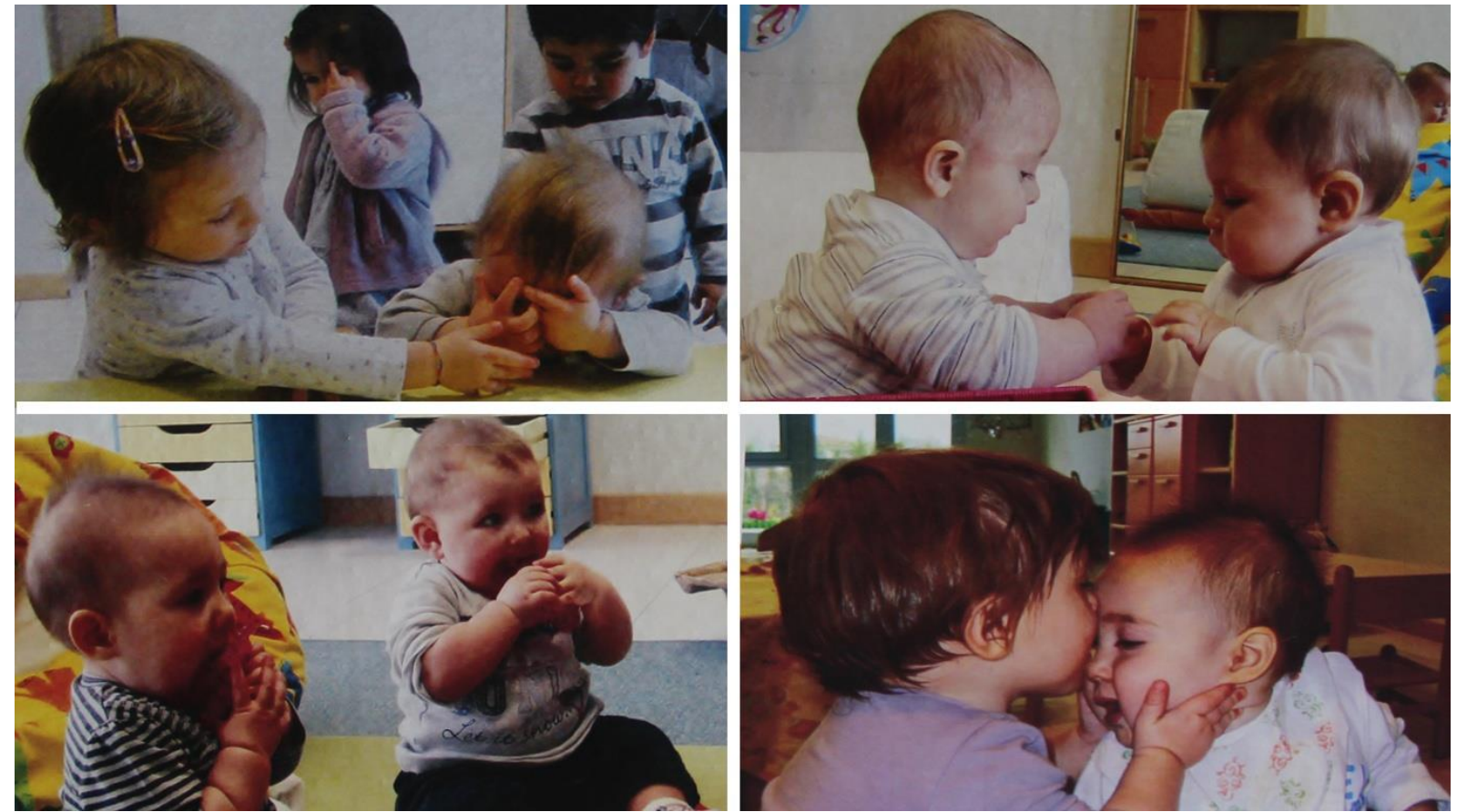

Fonte: Acervo da pesquisadora, 2014.

Nota: "Tudo acontece pela primeira vez. O assombro, a surpresa, a intensidade, a força, o prazer, o desprazer, o entusiasmo, a ternura... daquela primeira vez. A intensidade do compartilhamento de uma brincadeira. O prazer de compartilhar. O entusiasmo de um contato..." (Asilo Nido II Mulino, tradução nossa).

Ágil, desejante, desde os primeiros instantes de vida, o bebê interessa-se, movimenta-se, experimenta, interage com o outro e o mundo. Tudo lhe passa, acontece, vai ao seu encontro. Esse poder de busca emerge de sua curiosidade, abertura, sensibilidade (e por que não vulnerabilidade?). Condição primeira da experiência. Tomada no sentido empregado por Benjamin (1984), experiência pode ser lida como a arte do encontro capaz de afetar, produzir marcas e efeitos nos sujeitos implicados no processo. Uma possibilidade de acessar outra condição antes não entrevista, transformando a si mesmo e ao outro pela arte do encontro em um mesmo universo de prática e linguagem (PANDINI-SIMIANO, 2014).

Assumir imagem de criança, nessa perspectiva, remete a um encontro que nos lança em uma zona estranha, desconhecida, mas ao mesmo tempo nos interpela pelo fascínio de arriscar-se. Um convite a inverter o olhar e pensar em uma lógica que vê o bebê, situação de infans não como falta, mas como força, potência, capacidade.

A imagem de criança e o contexto no qual está inserida são fundamentais para a formulação de uma proposta educativa. A crença estabelecida na criança como autora, 
produtora de sentidos, necessita de um contexto educativo que privilegie suas relações, promovendo encontros capazes de afetar, produzir marcas e efeitos nos sujeitos implicados no processo.

Nesse sentido, apontamos um outro fio que sustenta as documentações pesquisadas; a presença de um contexto educativo que acolhe, amplia, potencializa e sustenta a experiência dos bebês. Uma das especificidades da pedagogia com os bebês é a sutileza, a forma indireta e discreta de constituir um contexto educativo, que, se bem organizado, propiciará relações educativas de qualidade. Tal contexto é estruturado a partir da organização dos espaços, dos usos do tempo, da seleção e oferta de materiais e de proposições de situações significativas.

Loris Malaguzzi, ao evidenciar o espaço no contexto educativo, concebendo-o como uma mensagem do projeto educativo. Ele elucida:

Valorizamos o espaço devido ao seu poder de organizar, de promover relacionamentos agradáveis entre pessoas de diferentes idades, de criar ambientes atraentes, de oferecer mudanças, de promover escolhas e atividades, e o seu potencial para iniciar toda a espécie de aprendizagem social, afetiva e cognitiva. Tudo isso contribui para uma sensação de bemestar e segurança nas crianças. Também pensamos que o espaço deve ser uma espécie de aquário que espelhe as idéias, atitudes e valores das pessoas que vivem nele. (MALAGUZZI, 1984 apud GANDINI, 2002, p. 97)

Nessa perspectiva, o espaço das instituições de Educação Infantil não pode ser concebido como pano de fundo e sim como parte integrante da ação pedagógica. Dessa forma, partimos do pressuposto de que a maneira como planejamos e organizamos os espaços, os materiais, os tempos coletivos de educação e cuidado dos bebês não é neutra, pois expõe uma intenção pedagógica e, ao mesmo tempo, pode nos revelar as concepções dos adultos sobre os bebês e crianças bem pequenas. Assim, é fundamental a criação de contextos que possibilitem a acolhida, o desafio, a exploração, a participação e expressão de crianças e adultos partilhando e comungando o mesmo espaço.

As creches em Pistóia destacam-se ao disponibilizar uma riqueza e diversidade de objetos e materiais no espaço. As salas parecem corresponder a um território de provocação, de convite à experimentação. Um reino de possibilidades em busca da 
expressão, a pesquisa articulando descoberta e aprendizagem. As crianças têm o direito de crescer em lugares cuidados, agradáveis; a educação não pode se eximir desse dever. Tal fato implica organizar uma proposta apta a envolver um contexto educativo repleto de possibilidades de experiências flexíveis à validação de outros modos de conhecer, qualificando sensibilidade, sentimento e intuição; uma proposta aberta ao estranho, ao incompreensível, ao inexplicável; trazendo, por isso, a pluralidade, acolhendo as diferenças, reconhecendo a incompletude dos saberes e fazeres e, portanto, pacientemente provendo o tempo necessário para este acontecer.

Figura 2: Documentação Tempo per crescere bene - Nido II Mulino
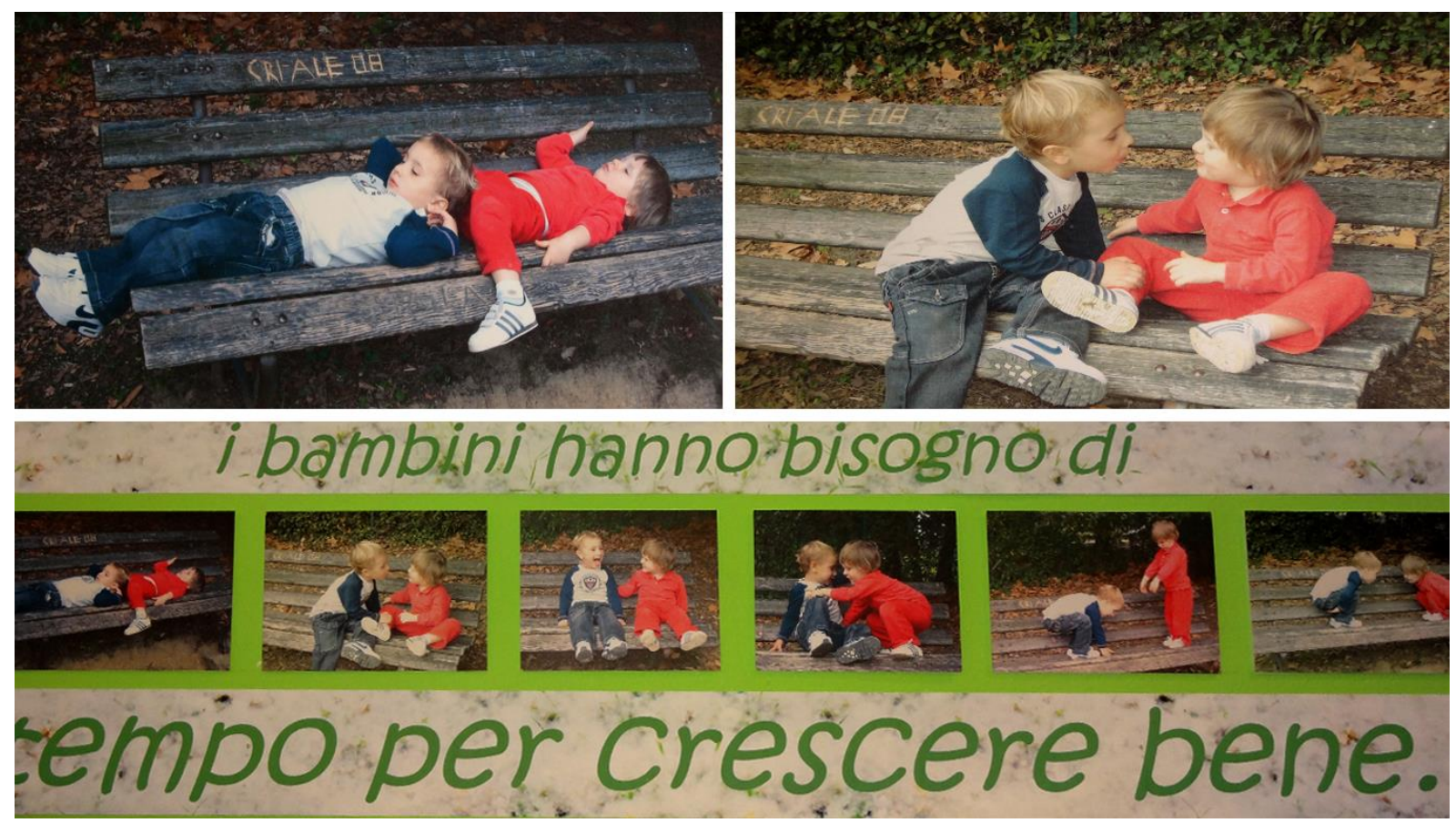

Fonte: Acervo da pesquisadora, 2014.

Nota: “As crianças precisam de tempo para crescer bem" (Asilo Nido Lago Mago, tradução nossa).

O tempo é um elemento fundamental para a especificidade que envolve a educação das crianças pequenas. O bebê precisa "ter tempo para brincar, fazer a mesma torre muitas vezes, derrubar, reconstruir, derrubar novamente, isso permite aos bebês sedimentar suas experiências" (BARBOSA, 2010, s/p). No ato de deixar as crianças transitarem livremente, disponibilizar espaços generosos e possibilitar tempos longos para suas descobertas, a professora cria um contexto que incentiva e sustenta a 
interação entre eles, assumindo, assim, um posicionamento de confiança na capacidade das crianças de viverem uma diversidade de relações no espaço educativo.

O tempo e o espaço são companheiros da experiência (BENJAMIN, 1986). A possibilidade de fazer experiência na creche, de fazer com que algo nos aconteça ou nos toque requer um gesto, pausa e interrupção para "abrir os olhos e os ouvidos, falar sobre o que nos acontece, aprender a lentidão, escutar aos outros, cultivar a arte do encontro, calar muito, ter paciência e dar-se tempo e espaço"(LARROSA, 2001, p. 20).Walter Benjamin já nos dizia que "o tempo das crianças não é um tempo do relógio, guiado pelo capital, não é o tempo homogêneo, mas um tempo saturado de 'agoras"' (BENJAMIN, 1984, p. 225, grifo do autor). Saibamos nós abrir nossos olhos, ouvidos e aprender sobre o tempo com as crianças.

Esses foram os fios comuns identificados. Amarrados em uma concepção, a documentação pedagógica sustenta uma criança ativa, capaz de crescer e se relacionar em um potente contexto educativo. O movimento dos fios da urdidura pedagógica acontece na relação. Entre adultos e crianças, criam-se laços...

\section{Os (entre) laçamentos na documentação pedagógica: sobre tecitura narrativa na creche}

$\mathrm{Na}$ creche, as práticas de cuidado e educação de bebês são múltiplas. Cada família tem um modo próprio de alimentar, embalar, acariciar, brincar, higienizar ou acalentar as crianças. Conhecer e considerar os saberes, as crenças, os valores, a diversidade de práticas sociais e culturais que cada grupo social tem para criar seus bebês é fundamental para a instituição educativa. É no estabelecimento de relações entre creche e família que se irá constituir o princípio que assegura à criança a continuidade e o enriquecimento de suas experiências educativas (CATARSI, 2013).

No sistema educativo de Pistóia, encontramos uma pedagogia cujo princípio é a criação de relacionamentos significativos na creche. Nas palavras de Galardini "a instituição educativa é uma trama de relações, onde o ato educativo se constitui a partir do significado do estar juntos, no encontro que produz um reconhecimento de si a partir do encontro com o outro" (GALARDINI, 2010, p.27). Tal proposta, acolhe, considera e 
valoriza os relacionamentos que se estabelecem entre as professoras, crianças e suas famílias.

É comum nas creches de Pistóia, o diálogo e a participação das famílias na construção de documentações. Essa busca se inicia desde o momento de chegada da criança à creche. As professoras, no intuito de conhecer mais sobre as crianças, convidam as famílias a coletar materiais, selecionar lembranças, marcas do seu cotidiano para compartilhar um pouco de sua cultura e costumes.

Na construção da documentação "Piccole Storie della Nanna”, os familiares são convidados a registrar, por meio de uma pequena história, os rituais cotidianos em que a criança adormece. As crianças levam para casa um pequeno bloco e uma caixa para registrar por escrito e com fotografias suas histórias junto à família. A professora acolhe as histórias contadas pelas famílias e paralelamente, observa, registra e documenta também histórias de repouso na creche. Esses momentos significativos, posteriormente são compartilhados.

Figura 3: Documentação Piccole Storie della Nanna- Nido Il Grillo

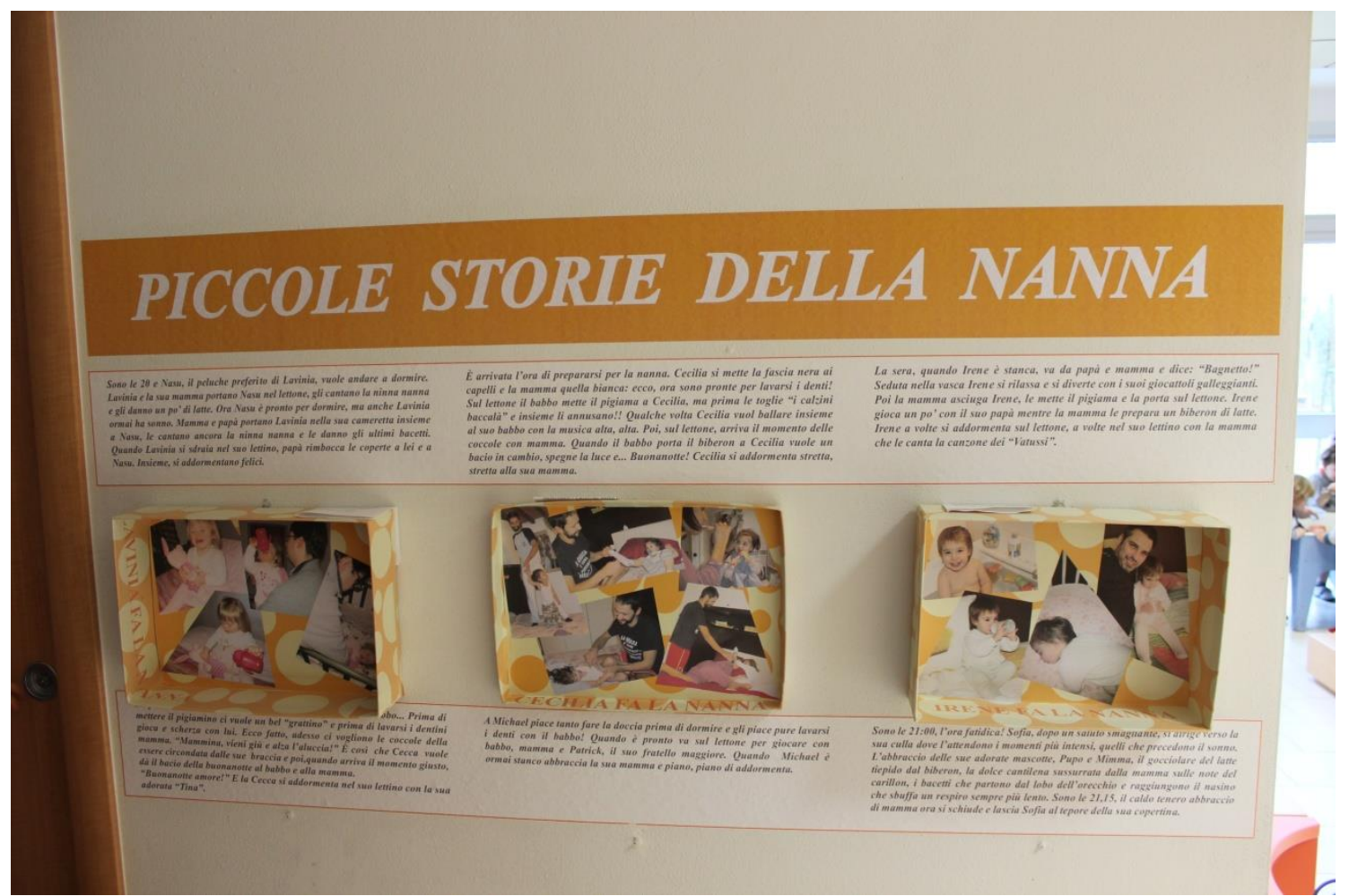

Fonte: Acervo da pesquisadora, 2014.

Nota: "Pequenas histórias de nanar" (Asilo Nido Il Grillo, tradução nossa). 
Uma canção de ninar, uma poesia, uma história, um bicho de pelúcia preferido, um paninho especial... O que implica marcar, documentar as histórias cotidianas das crianças? Os primeiros dias de frequência na creche são um período complexo. Nesse contexto, as crianças fazem as primeiras experiências de convivência no contexto coletivo. Guardar o singular de cada criança nesse espaço significa estar à disposição daquele que chega, respeitando sua alteridade. Para Silva (2013), "a consciência das diferenças e a capacidade de acolher as situações peculiares permitirá a educadora enfrentar a inserção das crianças na creche com paciência e atenção instalando um diálogo com as famílias" (SILVA, 2013, p.22).

O gesto de documentar a experiência cotidiana abre possibilidades de diálogo, compartilhamento e construção de uma história coletiva. Acolher a alteridade, registrar a singularidade na creche possibilita um sentido de pertença. Para que as crianças se reconheçam como sujeitos históricos, que fazem parte de um coletivo e que deixam marcas e constroem narrativas, é preciso construir, com elas, um percurso que contenha suas histórias de vida. No encontro entre professoras, crianças e suas famílias há a criação de uma narrativa capaz de sustentar o reconhecimento à valorização da experiência, da produção de sentido e da condição de pertença.

As documentações pedagógicas compostas de palavras, imagens e textos tecem histórias. Nessas materialidades trama-se momentos da vida. Possibilidades de construção de sentido. Não é uma forma de arquivo, Benjamin (1994) sustenta que experiência não se arquiva, é uma borda de sentido, um roçar em nossos sentidos podendo evocar, assim, experiência.

As "vozes das histórias" narradas pelas crianças, professores e familiares possibilitam diversas leituras. Textos, imagens e outras produções estabelecem diálogos, ampliam significados e possibilitam revisitar e constituir experiências significativas. Professora, crianças e familiares eram, simultaneamente, testemunhas, autores e leitores de uma história tecida no encontro no laço com o outro. Um tecido narrativo constituído na relação entre bebês e adultos.

Nessas documentações, cria-se visibilidades, não apenas para o que é aparente, pois "o significado documental não surge da mera observação. É sempre um ato interpretativo em que o documentador se implica autobiograficamente - no processo 
documental” (HOYUELOS, 2006, p. 203). Assim, a documentação pedagógica não pode ser compreendida como coleta e agrupamento de episódios isolados, visando a dar informações que têm como produto um relatório. Implica um processo que diz respeito ao uso desse material, à forma como ele é coletado, refletido, interpretado, inventado e, sobretudo, narrado.

Benjamin (1994), ao estabelecer relações entre experiência e narrativa afirma o vínculo entre o episódio narrado e a vida do narrador, afirmando que "se imprime na narrativa a marca do narrador, como a mão do oleiro na argila do vaso" (p. 227). A narração não está interessada em apenas transmitir “o puro em si” da coisa narrada como um relatório. Em contraposição à informação, a narração prescinde de explicações, deixando ao interlocutor a liberdade de interpretação. Acreditamos que tal movimento permite criar laços. Crianças, suas famílias e professora inscrevem nas documentações pequenas histórias: olhares, sentidos, gestos a serem inventados, decifrados, valorados, ressignificados na relação com o outro.

Propõe-se a documentação pedagógica como uma peculiar narrativa da experiência educativa tecida no encontro, na relação entre crianças e adultos (PANDINISIMIANO, 2015). Pequenos contos, estórias que possibilitarão caminhar por viagens, para lugares conhecidos e desconhecidos. Na documentação, a narrativa não se completa. Fios ficam soltos, convidando a novas tramas, abrindo possibilidades de produção de sentidos e significados entre crianças pequenas e adultos.

\section{O arremate... Pontos finais para esse tempo de estudo}

Frente à fragilidade da condição humana e às desmesuras do humano, aposta-se na narrativa como forma de construir outros sentidos e possibilidades de pertencimento. Nesse sentido, a educação infantil possui lugar e função fundamental. Desde a mais tenra idade, o encontro com a alteridade é capaz de criar novas formas de estar e habitar o mundo. No presente texto, a partir do recorte de uma pesquisa de doutorado em educação desenvolvida em creches italianas, apresentaram-se fragmentos que apostamos serem significativos para lançar outros olhares para o processo de documentação pedagógica e para a possibilidade de compor outras narrativas sobre o ser bebê, sobre ser professor e sobre o estar na creche. Sabe-se o quanto a organização das 
práticas pedagógicas cotidianas é um dos principais nós na pedagogia. Com bebês e crianças bem pequenas, tal nó pode ser ainda mais significativo. É possível compor narrativas atentas às singularidades, à coletividade, à experiência dos/com bebês na creche? Como ocupar tal função de ler e narrar o cotidiano? "Quem ainda encontra pessoas que saibam contar histórias como elas devem ser contadas?" (BENJAMIN, 1986, p. 114).

Assumir a documentação pedagógica como um processo narrativo nos lança em uma zona incerta e fascinante. Trata-se não apenas da aquisição de uma técnica, um conjunto prescritivo de procedimentos, mas de uma ética como uma tomada de posição. Ética como condição de possibilidade de um encontro, de uma experiência educativa constituída na relação, no laço com o outro.

\section{Referências}

BARBOSA, Maria Carmen Silveira. Por amor e por força: rotinas na educação infantil. Porto Alegre: Artmed, 2006.

BARBOSA, Maria Carmen Silveira. As especificidades da ação pedagógica com os bebês. Brasília: Consultoria Pública, 2010.

BENJAMIN, Walter. Rua de mão única: obras escolhidas II. 4. ed. São Paulo: Brasiliense, 1994.

BENJAMIN, Walter. Magia e técnica, arte e política: obras escolhidas I. 2. ed. São Paulo: Brasiliense, 1986.

BENJAMIN, Walter. Obras escolhidas I: magia e técnica, arte e política. 4. ed. Tradução de Sérgio Paulo Rouanet. São Paulo: Brasiliense, 1984. 
CATARSI, Enzo. Cura e incoraggiamento per la crescita dei bambini e delle bambine. In: CATARSI, Enzo. FRESCHI, Enrica (Orgs). Le ativitàdi cura nel nido d'infanzia. Parma: Edizioni Junior, 2013.

EDWARDS, C.; GANDINI, L.; FORMAN, G. As cem linguagens da criança: a abordagem de Reggio Emília na educação da primeira infância. Porto Alegre: Artmed, 2002.

FREIRE-WEFFORT, Madalena. Observação, registro, reflexão: instrumentos metodológicos I. São Paulo: Espaço Pedagógico, 1995.

GALARDINI, Anna Lia. Intrecci com la comunità. In: BECCHI, E. (Org.) Una pedagogia delbuongusto: esperienze e progetti dei servizi educativi per l'infanzia Del Comune di Pistoia. Milano: Franco Angeli, 2010.

EDWARDS, Carl; GANDINI, Lella; FORMAN, George. As cem linguagens da criança: a abordagem de Reggio Emília na educação da primeira infância. Porto Alegre: Artmed, 2002.

GANDINI, Lella. História, ideias e filosofia básica. Entrevista com Loris Malaguzzi. In: EDWARDS, Carl. Bambini: a abordagem italiana à educação infantil. Porto Alegre: FGV, 2002. cap. 2, p. 59-104.

HOYUELOS, Alfredo. La ética nel pensamiento y obra pedagógica de Loris Malaguzzi. Barcelona: Octaedro, 2004.

HOYUELOS, Alfredo. La estética e nel pensamiento y obra pedagógica de Loris Malaguzzi. Barcelona: Octaedro, 2006.

KOHAN, Walter. O. Infância, estrangeiridade e ignorância: ensaios de filosofia e educação. Belo Horizonte: Autêntica, 2007.

LARROSA, Jorge. (Org.). Imagens do outro. Petrópolis, RJ: Vozes, 1998.

LARROSA, Jorge. Notas sobre a experiência e o saber da experiência. Leituras da Secretaria Municipal de Campinas, Campinas, n. 04, jul. 2001.

MALAGUZZI, Lóris. La educación Infantil em Reggio Emilia. Barcelona: Ediciones Ectaedro, 2001.

MALAGUZZI, Lóris. Histórias ideias e filosofia básica. In: EDWARDS, Carolyn; GANDINI, Lella; FORMAN, George. As cem linguagens da criança. Porto Alegre: Artes Médicas, 1999. p. 48-62.

MALAGUZZI, Lóris. La storia, le ideie, le cultura. I cento linguaggio dei bambini. Bergamo: Edizione Junior, 1995. 
OSTETTO, Luciana Esmeralda. Observação, registro, documentação: nomear e significar as experiências In: OSTETTO, Luciana Esmeralda (Org.) Educação infantil: saberes e fazeres da formação de professores. Campinas, SP: Papirus, 2008.

PANDINI-SIMIANO, Luciane. Colecionando pequenos encantamentos: a documentação pedagógica como uma narrativa peculiar para e com crianças pequenas. 2015. 162 f. Tese (Doutorado em Educação) - Universidade Federal do Rio Grande do Sul, Programa de Pós-Graduação em Educação, Porto Alegre, 2015.

PANDINI-SIMIANO, Luciane. Medidas de um outro olhar... sobre a materialidade do espaço da creche e a constituição de um lugar dos bebês. Arquivos Analíticos de Políticas Educativas: v. 22, n. 1, p. 1-15, set. 2014.

RINALDI, Carla. A imagem da criança e o ambiente em que ela vive como principio fundamental. In: EDWARDS, Carolyn. Bambini: a abordagem italiana à educação infantil. Porto Alegre: FGV, 2002. cap. 4, p. 75-81.

RINALDI, Carla. Diálogos com Reggio Emilia: escutar, investigar e aprender. São Paulo: Paz e Terra, 2012.

RINALDI, Carla. Observation and documentation. Document in Reserarch Conference. Reggio Emilia: Junio, 1995.

SILVA, Clara Maria. Cura e intercultura nella percezione delle educatrici dei nidi toscani. IN: CATARSI, Enzo. FRESCHI, Enrica. (Orgs). Le ativitàdi cura nel nido d'infanzia. Parma: Edizioni Junior, 2013. 